\title{
2017 Corrections
}

\section{Erratum}

To the article "Antitumor activity of carboplatin in the composition of a copolymer of lactic and glycolic acids," by E. D. Nikolskaya, O. A. Zhunina, N. G. Yabbarov, V. A. Zenin, O. G. Tereshchenko, M. V. Fomicheva, M. B. Sokol, A. V. Lobanov, and E. S. Severin, Vol. 66, No. 10, pp. 1867-1872, October, 2017.

In the original international version of the article, seventh author's name was omitted. In should be M. R. Faustova. 